\title{
Landscape-scale mass-action of spiders explains early-season immigration rates in crops
}

\author{
F. J. J. A. Bianchi - B. J. Walters - S. A. Cunningham - L. Hemerik • \\ N. A. Schellhorn
}

Received: 20 November 2015/Accepted: 7 April 2017/Published online: 17 April 2017

(C) The Author(s) 2017. This article is an open access publication

\begin{abstract}
Context Early-season immigration into arable fields by natural enemies is key for effective biocontrol, but little is known about the mechanisms underlying immigration processes.

Objectives Here we test the mass action hypothesis for ballooning spiders, stating that local immigration rates are positively related to the amount of spiders in the surrounding landscape.

Methods Immigration rates of spiders were assessed by sticky traps in remnant vegetation, in arable land 25-125 m from remnant vegetation, and in arable land further than $400 \mathrm{~m}$ from remnant vegetation. The experiment was conducted at 18 locations across two landscapes and repeated three times in a 2-week period in 2007 and 2008. Spider densities in crop and non-
\end{abstract}

Electronic supplementary material The online version of this article (doi:10.1007/s10980-017-0518-7) contains supplementary material, which is available to authorized users.

F. J. J. A. Bianchi - B. J. Walters - N. A. Schellhorn CSIRO, P.O. Box 2583, Brisbane, QLD 4001, Australia

F. J. J. A. Bianchi - B. J. Walters - S. A. Cunningham N. A. Schellhorn

Cotton Catchment Communities CRC, Australian Cotton Research Institute, Narrabri, NSW 2390, Australia

\section{F. J. J. A. Bianchi ( $\square)$}

Farming Systems Ecology, Wageningen University, P.O. Box 430, 6700 AK Wageningen, The Netherlands e-mail: felix.bianchi@wur.nl crop habitats were assessed by beat sheet sampling and used to calculate spider loads in landscape sectors around the experimental locations at five spatial scales.

Results Regression analysis indicated that immigration rates were influenced by meteorological variables and landscape context at $2 \mathrm{~km}$ and possibly beyond. Regression models that included spider load at relevant spatial scales received more statistical support from the data than models with the proportion of remnant vegetation and crops. Regression analysis further indicated that wheat and - to a lesser extentremnant vegetation are important habitats for the recruitment of ballooning spiders.

Conclusions Our study provides support for the mass action hypothesis by showing that a combination of land-use variables with habitat specific spider densities allows the generation of functional cover types with greatly improved explanatory power.

\footnotetext{
S. A. Cunningham

CSIRO, P.O. Box 1700, Canberra, ACT 2601, Australia

L. Hemerik

Biometris, Wageningen University, P.O. Box 16, 6700 AA Wageningen, The Netherlands

S. A. Cunningham

Fenner School of Environment and Society, Australian

National University, Canberra, ACT 2602, Australia
} 
Keywords Agroecosystem - Ballooning - Dispersal · Spatial ecology $\cdot$ Landscape ecology

\section{Introduction}

There has been considerable interest in measuring arthropod movement in agricultural landscapes and identifying landscape features associated with increased natural enemy densities and biocontrol services (Chaplin-Kramer et al. 2011; Schellhorn et al. 2014). However, progress into identifying mechanisms that explain and predict how landscape features influence the spatial distribution of arthropods and ecosystem services has been limited (Kremen 2005). On the one hand, there are mechanistic models that incorporate population dynamics and dispersal processes and generate predictions of features of pest suppressive landscapes (e.g., Bianchi et al. 2010), but typically these models are not based on sampling data of pests and natural enemies (but see Thorbek and Topping 2005). On the other hand there are many correlative studies that relate local population measurements to metrics of the surrounding landscape (e.g. Thies and Tscharntke 1999). Typically landscape metrics are expressed as land use classes, e.g. proportion non-crop habitat. Yet, land use classes may not always capture the underlying drivers of biocontrol, such as population processes and population densities of natural enemies. Indeed, patches of the same land use class may vary greatly in function due to presence of different plant species (Bianchi et al. 2012) or practices such as insecticide application (Macfadyen et al. 2014). The concept of functional cover types (Fahrig et al. 2011) may be used to link these conceptual and empirical approaches, allowing the generation of biologically underpinned land-use types with potentially better explanatory power.

Mass action provides a mechanism that may be useful for explaining the immigration of arthropods to arable crops. Originating from chemistry, the law of mass action states that that rate of a process is proportional to the masses of the reacting substances (Encyclopædia Britannica 2015). An example of mass action in ecological literature is provided by the Lotka-Volterra equations describing predator-prey dynamics where the predation rate is assumed to be proportional to the number of predators and prey that meet. Related examples include spill-over effects, i.e. the mass movement of individuals from high productive habitats to surrounding habitats where the immigration rate may be related to the number of individuals in the productive habitat (Rand and Louda 2006), and high immigration rates of pollinators into mass-flowering crops due to the presence of a massive food resource (Holzschuh et al. 2013). While spillover and aggregation studies typically focus on the situation before and after population redistribution, mass action explicitly centres on the rate at which this process takes place. We hypothesise that mass action may also be useful to explain immigration rates of natural enemies into newly cultivated arable fields. While mass action may have potential as a predictor for local levels of ecosystem service provision, we are unaware of empirical examples demonstrating its application.

Ballooning spiders can be important predators of insect pests (Symondson et al. 2002), and their local abundance can be influenced by landscape context, in particular non-crop habitat (Schmidt and Tscharntke 2005a, b, Gavish-Regev et al. 2008; Schmidt et al. 2008, but see Pluess et al. 2010). Because of their semi-passive mode of dispersal, we hypothesise that ballooning spider movement in landscapes and the subsequent immigration into crops may follow the principle of mass action. While the physics associated with spider ballooning has been well studied (Thomas et al. 2003; Reynolds et al. 2007), and responses to landscape context have been documented (Clough et al. 2005; Schmidt and Tscharntke 2005a; Schmidt et al. 2008), a mechanistic explanation of the relationship between spider immigration and landscape context is still lacking.

This 2-year study focuses on the immigration of ballooning spiders early in the growing season as this period is considered critical for effective suppression of pest populations that have potential for exponential increase (Schellhorn et al. 2014). The aim of this study is threefold. First, we assess how the distance from remnant vegetation, a potential source of spiders, influences spider immigration rates. For this purpose we quantified immigration rates of spiders in, adjacent to and further than $400 \mathrm{~m}$ from patches of remnant vegetation. Second, we compare the explanatory power of variables based on land-use categories versus estimates of the number of spiders (referred to as "spider load"). Here, we started with an approach 
similar to many other studies of agroecosystems, in which land was categorised in two land-use categories (crop and woody native vegetation), and tested how well these land-use variables predicted the number of spider immigrants. We then developed a model where crops and woody native vegetation were assigned a specific spider density based on survey data. These data were used to estimate spider loads around each location, which were then used as predictors of spider immigration. Third, we assess which crop and vegetation types contribute to the recruitment of immigrating spiders in more detail by testing crop-specific spider loads and spider loads in woody remnant vegetation as predictors of spider immigration.

\section{Materials and methods}

The study was conducted at 18 locations spread among two $5 \mathrm{~km}$ radius landscape sectors in an arable production area, near Dalby, Queensland, Australia. The areas were $50 \mathrm{~km}$ apart, with the centres located at $1516^{\prime} 2.28^{\prime \prime} \mathrm{E} ; 2651^{\prime} 31.52^{\prime \prime} \mathrm{S}$ (North landscape) and $1515^{\prime} 47.83^{\prime \prime} \mathrm{E} ; 2717^{\prime} 43.43^{\prime \prime} \mathrm{S}$ (South landscape), and contained 6 and $13 \%$ native vegetation, respectively. The median annual precipitation ranges between 600 and $800 \mathrm{~mm}$, but rainfall patterns within and between years are erratic. The landscapes consisted of agricultural fields, including sorghum (Sorghum bicolor L. Moench), barley (Hordeum vulgare L.), canary (Phalaris canariensis L.), chick pea (Cicer arietinum L.), wheat (Triticum aestivum L.) and cotton (Gossypium hirsutum L.), as well as grassland, bare-soil stubble and remnant woody native vegetation in various forms (linear strips of trees, patches of remnant vegetation and remnant vegetation along creeks; Table 1). Chick pea is a spring crop planted in July, sorghum and cotton are summer crops and planted around September/October, while wheat, barley and canary are winter crops which are planted in late May and harvested from September till December. Cotton is often irrigated, but also grown as dryland crop. The plant species composition of the woody remnant vegetation was similar in both landscapes with Eucalyptus populnea (F. Muell.), Acacia salicina (Lindl.) and A. harpophylla (F. Muell.) dominant in the tree and shrub layer, and several chenopodiaceous species in the understory (Bianchi et al. 2012).
Spider immigration was assessed in October 2007 and 2008 around the time when summer crops were planted and crop immigration by spiders is likely to start. In each landscape, plots were established in, near and far from woody remnant vegetation and replicated three times. Plots in patches of woody remnant vegetation consisted of 12 sampling stations that were laid out in a $4 \times 3$ grid $(75 \mathrm{~m} \times 50 \mathrm{~m})$ at the border of the adjoining arable field (Online Appendix 1). Plots near woody remnant vegetation consisted of 20 stations in a $4 \times 5$ grid $(75 \mathrm{~m} \times 100 \mathrm{~m})$ that were placed in arable fields at $25 \mathrm{~m}$ from the edge of the woody remnant vegetation plots. Plots far from woody remnant vegetation also consisted of 20 stations in a $4 \times 5$ grid $(75 \mathrm{~m} \times 100 \mathrm{~m})$ placed in arable fields at least $400 \mathrm{~m}$ from woody remnant vegetation. In all plots trapping stations were spaced $25 \mathrm{~m}$ apart. In total, there were 18 plots ( 2 landscapes $\times 9$ plots) in each year.

Sampling stations consisted of four sentinel cotton seedlings and a sticky trap (plant assessments reported in Bianchi et al. 2015). Cotton plants were used in bare-soil fields with cereal stubble to mimic newly emerging cotton fields, as summer crops are directly sown into stubble in no-till systems. In 2008 the baresoil cereal stubble fields also contained newly emerging sorghum, which were $13.6 \pm 1.56 \mathrm{~cm}$ high (mean \pm SEM) at the start of the experiment. Cotton seedlings were five weeks old (height $6-10 \mathrm{~cm}, 2-4$ leaf stage). Sticky traps consisted of transparent polypropylene cups (height $13 \mathrm{~cm}$, diameter 5.5-9 $\mathrm{cm}$ ) covered with a thin layer of transparent 'tangletrap' (Australian Entomological Supplies Pty. Ltd) diluted with hexane (1:4 parts) for easy spreading. The cups were fixed upside down on sticks placed in the ground such that ballooning spiders at $20 \mathrm{~cm}$ above the soil were captured. Spiders were unable to climb onto the traps. The number of spiders per trap was assessed under 10 times magnification in the laboratory.

In both years, 3 independent assessments of spider immigration rates were made across a 12-day window in the early growing season. Sticky traps and sentinel cotton plants were out for approximately 3 days in 3 replicated time periods, referred to as period 1, 2 and 3 . There was one-day break in between periods. Starting dates in 2007 and 2008 were 13 and 17 October, respectively. New sticky traps and sentinel plants were deployed for each period. In summary, the design 
Table 1 Overview of spider sampling data

\begin{tabular}{|c|c|c|c|c|c|c|c|}
\hline \multirow[t]{2}{*}{ Landscape } & \multirow{2}{*}{ Land use type } & \multicolumn{3}{|l|}{2007} & \multicolumn{3}{|l|}{2008} \\
\hline & & Area (ha) & Spider density $\left(\mathrm{m}^{-2}\right)$ & $\overline{\mathrm{n}}$ & Area (ha) & Spider density $\left(\mathrm{m}^{-2}\right)$ & $\mathrm{n}$ \\
\hline \multirow[t]{9}{*}{ North } & $\begin{array}{l}\text { Remnant } \\
\text { vegetation }\end{array}$ & 514.5 & 1.10 & 4 & 514.5 & 4.12 & 4 \\
\hline & Sorghum & 3464.0 & 0.11 & 2 & 2410.4 & 1.09 & 7 \\
\hline & Wheat & 2362.3 & 0.30 & 1 & 2562.4 & 6.78 & 3 \\
\hline & Barley & 413.5 & 0.60 & 1 & 426.2 & 0.30 & 1 \\
\hline & Cotton & 189.5 & - & - & 0 & - & - \\
\hline & Chick pea & 83.6 & - & - & 364.2 & 0.15 & 1 \\
\hline & Canary & 93.5 & 0 & 1 & 0 & - & - \\
\hline & Bare-soil stubble & 2269.9 & - & - & 2938.2 & - & - \\
\hline & Grassland & 1671.9 & - & - & 1671.9 & - & - \\
\hline \multirow[t]{9}{*}{ South } & $\begin{array}{l}\text { Remnant } \\
\text { vegetation }\end{array}$ & 1129.8 & 4.32 & 6 & 1129.8 & 4.19 & 6 \\
\hline & Sorghum & 1831.9 & 0.22 & 1 & 2451.5 & 0.52 & 6 \\
\hline & Wheat & 1223.9 & 0.38 & 4 & 1358.5 & 2.26 & 4 \\
\hline & Barley & 48.8 & - & - & 56.6 & 1.21 & 1 \\
\hline & Cotton & 5.9 & - & - & 237.0 & - & - \\
\hline & Chick pea & 278.4 & 0.07 & 2 & 164.9 & 0 & 1 \\
\hline & Canary & 0 & - & - & 0 & - & - \\
\hline & Bare-soil stubble & 1463.1 & - & - & 1520.3 & - & - \\
\hline & Grassland & 1542.6 & - & - & 1542.6 & - & - \\
\hline
\end{tabular}

Area of land-use types (ha) in the North and South landscape (5-km radius) in October 2007 and 2008, mean spider density (m ${ }^{-2}$ ) as assessed by beat sheet sampling, and number of remnant vegetation patches and fields sampled (n). Spider densities in woody remnant vegetation represent summed spider densities on native plant species, accounting for plant species height and vegetation cover in remnant vegetation patches. The area of land-use types include 2-km radius landscape sectors around experimental plots, hence the summed land-use area can exceed the area of a 5-km radius landscape (7854 ha)

included 108 plots with 1872 traps: 3 treatments (within + adjacent + far $=12+20+20=$ 52 traps $) \times 3$ spatial replicates $\times 2$ landscapes $\times 3$ periods $\times 2$ years.

At the same time that immigration of spiders was assessed using sticky traps, spider density was assessed by beat sheet sampling in October 2007 and 2008 (Bianchi et al. 2012). Arthropods were sampled within $1.5 \mathrm{~m}$ of a row (in crops) or individual plants or trees (in remnant vegetation) by dislodging from the plants with a stick onto a $2.5 \times 1.5 \mathrm{~m}$ yellow beat sheet. Sampled crops included sorghum, wheat, chick pea, barley and canary, while E. populnea, A. salicina, and the chenopodiaceae Enchylaena tomentosa (R. $\mathrm{Br}$.), Atriplex muelleri (Benth.), Sclerolaena muricata (Moq.), Rhagodia nutans (R. Br.) and Maireana microphylla (Moq.) were sampled in woody native vegetation. In 2007 and 2008, the same woody remnant vegetation patches were sampled in the North (four patches) and South landscape (six patches), respectively. In 2007, all woody remnant vegetation patches in which spider immigration was quantified using sticky traps were also sampled by beat sheet. However, this was not possible for all remnant vegetation patches in 2008 because in some cases there was no cereal stubble field with sorghum seedlings adjacent to these patches. Fields were selected for beat sheet sampling based on crop types, which could be similar or different fields in 2007 and 2008. In 2007, 53 crops and native plants were sampled (for a total of 250 beat sheet samples) and in 2008, 62 crops and native plants were sampled (for a total of total 303 beat sheet samples). To convert spider densities in crops and native plants to 
landscape-scale spider-load estimates, the number of spiders collected on beat sheets were converted to plant-specific density estimates using data on row spacing (for crops), crown projection area of Chenopodiaceae (as crown projection area was lower than the area of beat sheets), vegetation height and plant species cover (for plant species in woody native vegetation). These calculations were conducted separately for both landscapes and years to account for landscape and year specific spider densities and cover of native plants (Table 1). Land use around each plot was assessed by quantifying the areas of woody remnant vegetation, grassland, bare-soil stubble, sorghum, barley, canary, chick pea, wheat and cotton (in ha) in circles with radii of 100, 500, 1000, 1500 and $2000 \mathrm{~m}$ using ground survey and ArcGIS. Estimates of the spider load in these landscape sectors around plots were derived by multiplication of the area of the habitat types with the density of spiders per habitat type (Table 1). We did not systematically sample minor crop types in the study area, and spider densities in grassland and bare-soil stubble was not assessed as beat sheet sampling is not effective in these habitats. For the calculation of spider load we assumed that habitats that were not sampled did not support spiders. As spiders are likely to be present in these habitats, the spider load is a conservative estimate of the amount of spiders.

In each landscape we took half-hourly records of temperature, precipitation, wind, and dew point temperature using a Davis Vantage Pro2 weather station (South Windsor, Australia). We used the daily aeronautic index as a proxy for spider ballooning conditions, with high aeronautic index values indicating favourable conditions. Aeronautic indices were derived by dividing the daily range of temperature $\left({ }^{\circ} \mathrm{C}\right)$ by the mean daily wind speed (Vughts and van Wingerden 1976). Aeronautic indices for the multiday sampling periods were obtained by averaging daily aeronautic indices weighted with the proportion of the day that traps were operational in the field.

\section{Data analysis}

Spiders on sticky traps were analysed as count data. Four discrete stochastic distributions were considered for the error distribution of the data: Poisson, negative binominal, zero-inflated Poisson and zero-inflated negative binominal. The zero-inflation factor of the zero-inflated distributions and the overdispersion parameter $k$ of the negative binominal distribution were assumed equal across treatments (i.e., in, adjacent to and far from woody remnant vegetation) to avoid overparameterization. The models were fitted using glm (for Poisson distribution), glm.nb (for negative binominal distribution) and zeroinfl functions (for zero inflates Poisson and negative binominal distributions) using the $\mathrm{R}$ packages MASS (Venables and Ripley 2002) and PSCL (http://cran.r-project.org/ web/packages/pscl/pscl.pdf).

Akaike's Information Criterion, corrected for finite sample sizes $\left(\mathrm{AIC}_{\mathrm{c}}\right)$, was used to rank and select models (Burnham and Anderson 2002). The negative binominal distribution gave a slightly better fit than the zero-inflated negative binominal distribution, but the model selection results for both distributions were very similar. Here we present the results of the negative binominal distribution for all analyses. Model selection of explanatory variables was conducted using the dredge procedure in $\mathrm{R}$ package MuMIN (http://cran.r-project.org/web/packages/ MuMIn/MuMIn.pdf). This procedure generates a complete set of sub-models with combinations of the terms of the full model, and sorts the sub-models on the basis of $\mathrm{AIC}_{\mathrm{c}}$ values and associated Akaike weights.

We conducted three different analyses with our data. In the first analysis we considered variables that were part of the experimental design, i.e. treatment (plots adjacent to and far from native vegetation, and plots within native vegetation), period, landscape, and year. These factorial explanatory variables account for variation in the biophysical system that may drive the immigration process of spiders, but do not specify the underlying components (e.g. the factor period may be influenced by various meteorological variables, such as wind and temperature). Two-way interactions between treatment and landscape, and year and period were also considered. To account for differences in the exposure time of sticky traps in the field we included the log-transformed exposure hours as an offset variable in the full model (Zuur et al. 2009). In biological terms this means that the response variable is now expressed as the number of spiders per unit of time.

A second analysis focused on the comparison between commonly used land use variables (proportion of native vegetation and crops) and more 
biologically meaningful spider load variables (estimated number of spiders in native vegetation and crops) to explain spider immigration. This analysis was conducted at five spatial scales (circles with radii of 100, 500, 1000, 1500 and $2000 \mathrm{~m}$ ). Spider loads were log-transformed because the estimated number of spiders included some very high values (particularly at larger spatial scales). In addition, temperature, wind, dew point temperature and aeronautic index were used to account for weather conditions. The variable "year" was also included and accounts for any effects of year, e.g. meteorological conditions in the period before exposure and the different vegetation background in plots in arable fields (bare-soil stubble vs. sorghum seedlings). The variable "hours of exposure" (log-transformed) was included as an offset variable in the global model, and no interactions between variables were included.

In a third analysis we considered a set of spider loads (log-transformed) for wheat, sorghum, barley, chickpea crops and woody remnant vegetation, as well as the meteorological variables and offset variable of the second analysis. This analysis provided further insight in the specific crop/vegetation types driving spider immigration.

\section{Results}

In 2007, 237 spiders were collected on sticky traps (mean \pm SEM: $0.253 \pm 0.018$, range $0-3$ ), whereas in 2008, 797 individuals were collected (mean \pm SEM: $0.852 \pm 0.036$, range $0-7$ ). The total number of spiders on traps in, adjacent to, and far from remnant vegetation was 197, 450 and 387, respectively. Beat sheet sampling of native plants and crops resulted in 409 spiders in 2007 (mean \pm SEM: $1.64 \pm 0.126$, range 0-11) and 1297 spiders in 2008 (mean \pm SEM: $4.28 \pm 0.290$, range 0-27). Spider densities were typically higher on native plants in remnant vegetation than in crops, and among crops, wheat supported relatively high spider densities (Fig. 1).

The model selection procedure of the first analysis, considering variables of the experimental design, indicated that the full model including interactions between year and period, and landscape and treatment received most support from the data. There were no alternative models selected within an envelope of $\Delta \mathrm{AIC}_{\mathrm{c}}$ of 2 . The model indicated that the number of spiders in, adjacent to and far from woody remnant vegetation were distinctly different in the North and South landscape, with the highest spider density in remnant vegetation in the south and in arable fields in the north landscape (Fig. 2). The number of spiders was the highest in 2008, and increased distinctly from the first period to the second, while in 2007 the spider immigration rate remained more or less constant during the three periods (Fig. 2).

The second analysis focusing on the explanatory power of land use and spider load variables indicated that there was general support for the spider load models at larger spatial scales (Table 2). While at a scale of $100 \mathrm{~m}$ both land use and spider load models received similar support from data $\left(\Delta \mathrm{AIC}_{\mathrm{c}}=0.1\right)$, and there was more support for the land use model than spider load model at $500 \mathrm{~m}\left(\Delta \mathrm{AIC}_{\mathrm{c}}=2.2\right)$, at spatial scales of $1000-2000 \mathrm{~m}$ the spider load models received clear support from data (Fig. 3). The $\mathrm{AIC}_{\mathrm{c}}$ values of the most parsimonious spider load models showed a declining trend with increasing spatial scale, indicating that spider immigration is influenced by the landscape context at relatively large spatial scales of $2000 \mathrm{~m}$ or beyond. The estimate of the explanatory variable "spider load" in crops and remnant vegetation was positive in all models, indicating that the spider load in the landscape was positively correlated with spider immigration rates. The most parsimonious model for $2000 \mathrm{~m}$ contained spider load in crops and woody remnant vegetation, aeronautic index, wind, temperature and the offset variable for the logtransformed exposure hours. The model indicated that spider immigration increased with higher spider loads in crops and remnant vegetation, and that spider immigration had a positive association with aeronautic index, wind speed and temperature (Table 3). Alternative models within $2 \mathrm{AIC}_{\mathrm{c}}$ points of the most parsimonious model indicate that there is also support for a positive effect of dew point temperature (indicating a higher spider immigration rate at lower relative humidity) and year (both selected in 3 out of 5 models), with higher spider immigration in 2008 than in 2007 (Online Appendix 2).

The third analysis focusing on spider loads in crop/ vegetation types associated with spider immigration indicated that spider immigration was positively associated with the spider load in wheat and woody remnant vegetation, and negatively associated with spider load in barley and chickpea. In addition, spider 


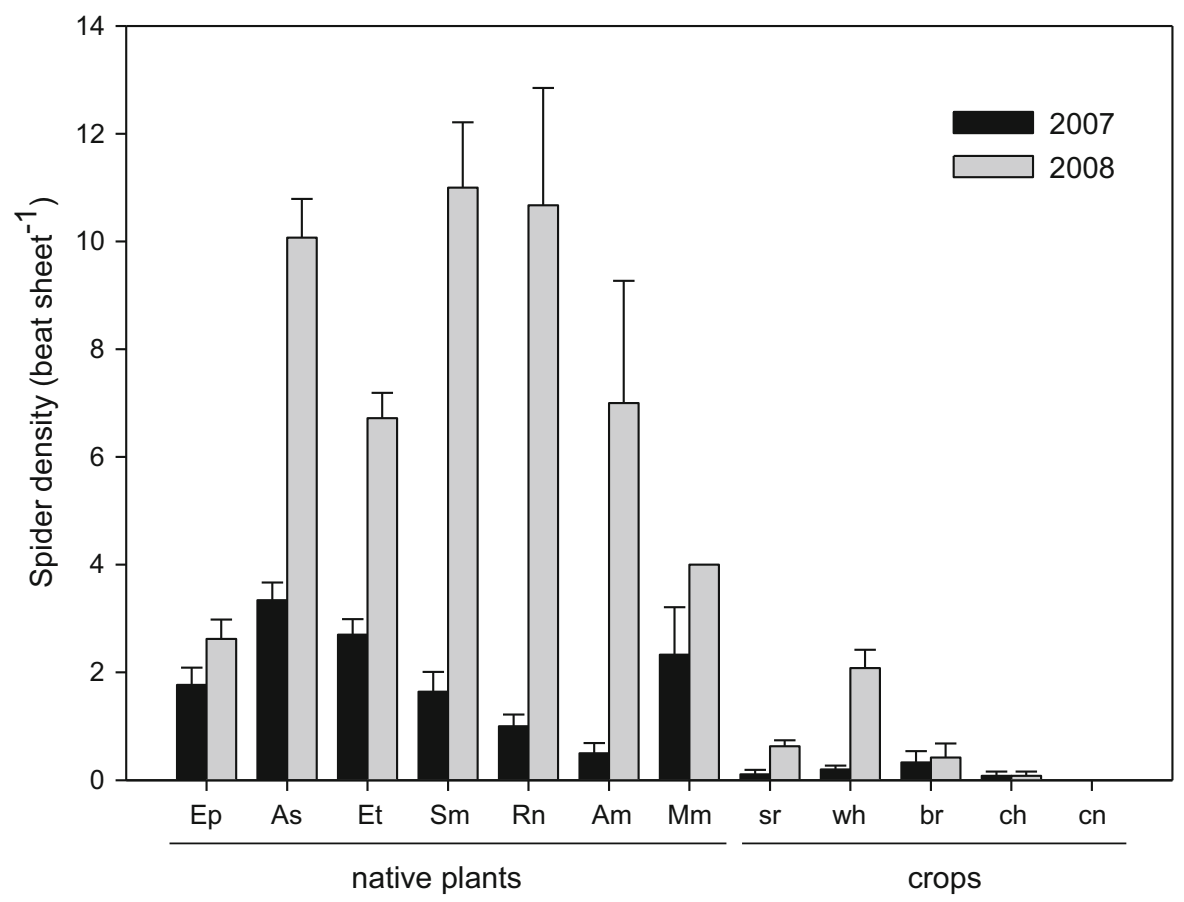

Fig. 1 Spider densities $( \pm$ SEM) on native plant species and crops in 2007 (black) and 2008 (grey). Plant species coding: Ep (Eucalyptus populnea), As (Acacia salicina), Et (Enchylaena tomentosa), Sm (Sclerolaena muricata), Rn (Rhagodia nutans),

immigration was positively associated with aeronautic index, wind and dew point temperature, and the offset variable was selected as well (Table 4). Alternative models within an envelope of 2 AIC points of the most parsimonious model show that there is also support for a positive effect of spider load in sorghum (selected in 4 out of 10 models), temperature (6 out of 10 ) and year (3 out of 10; Online Appendix 3).

\section{Discussion}

The immigration of natural enemies into arable fields is key for the effective control of pest populations in crops (Wissinger 1997; Schellhorn et al. 2014). Our data show that spider immigration into crops is a continuous process, occurring in all six discrete periods. However, immigration rates of ballooning spiders are highly dynamic with distinct differences between days and years, which are landscape specific. To understand the landscape drivers of spider immigration we compared variables based on land usebased metrics (proportion of crop and remnant
Am (Atriplex muelleri), Mm (Maireana microphylla), $\mathrm{sr}$ (sorghum), wh (wheat), br (barley), ch (chick pea) and canary (cn)

vegetation) and spider load, a biologically meaningful variable informed by assessment of spider densities in crop and non-crop habitats. Key findings of our study are that (i) the spider load model is superior to the land use model at relevant spatial scales, indicating that the habitat specific spider density values are useful in predicting spider immigration, (ii) wheat and woody remnant vegetation are important habitats for the recruitment of ballooning spiders, while the contribution of barley, chick pea and sorghum is limited, and (iii) immigration into arable fields is influenced by meteorological variables, and landscape context at $2 \mathrm{~km}$ radius and possibly beyond.

The finding that spider load at the landscape scale is a good predictor for immigration rates of ballooning spiders provides support for the mass action hypothesis. Ballooning spiders can move over long distances when taken up with wind currents (Reynolds et al. 2007; Schmidt et al. 2008), and their dispersal direction is governed by wind (Vughts and Wingerden 1976; Reynolds et al. 2007). Model simulations suggest that the proportion of habitats suitable for Linyphiid reproduction is of major importance for the 

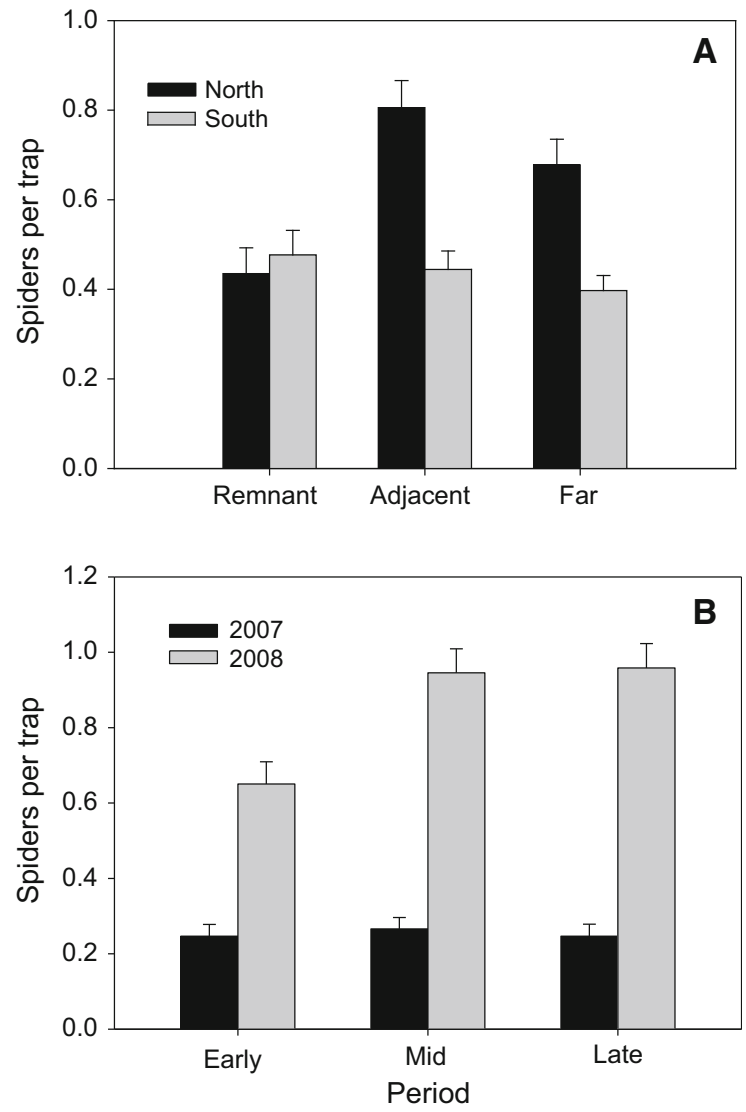

Fig. 2 Mean number of spiders per trap $( \pm$ SEM) in plots in, adjacent to and far from woody remnant vegetation in North (black) and South landscape (grey) (a), and in three periods in 2007 (black) and 2008 (grey) (b). Periods entailed 3-day intervals with a 1-day interval between them

population size, whereas the spatial arrangement of habitats is less important (Thorbek and Topping 2005). These simulation results are congruent with the concept of passive undirected movement. Based on these properties, the emergence of a mass action effect, i.e. increased immigration rates with a higher population of ballooning spiders in the surrounding landscape, is consistent with our understanding of the system, yet, no other published studies have reported such relationship. A limitation of our study is that we could not differentiate between immigrating and emigrating spiders on sticky traps. We assumed that all spiders on the traps were immigrants because we observed very few spiders in cereal stubble fields. However, in woody remnant vegetation plots it's possible that spiders leaving the experimental plots may have been captured as well. Another constraint of our study is that we did not differentiate between ballooning and non-ballooning spiders in the beat sheet sampling of habitats, because this is difficult in the field. Since only a fraction of the spider species disperse by ballooning, our sampling was potentially biased if the ratio ballooning-non-ballooning spiders was habitat specific. Nevertheless, spider load based variables were selected in the most parsimonious model at all spatial scales (Table 2), suggesting that even a potentially biased metric for ballooning spiders has good explanatory power.

Regression analysis indicated that wheat and woody remnant vegetation are important habitats for the recruitment of spiders for crop immigration, reflected by positive estimates for log-transformed spider loads in wheat and woody remnant vegetation of 0.40 and 0.19 , respectively (Table 4 ). While spider densities in wheat were lower than in woody remnant vegetation (Fig. 1), the model estimates suggest that a higher proportion of the spider population in wheat are recruited for crop immigration than in remnant vegetation. This result is in line with observations that crops are often dominated by spider species that have the ability to disperse by ballooning (Pearce et al. 2005; Gavish-Regev et al. 2008, Pluess et al. 2008) and that the ballooning propensity is higher in spiders originating from disturbed habitats, such as crops, than from undisturbed habitats, such as remnant vegetation (Entling et al. 2011). Furthermore, increased spider ballooning from wheat crops could have been triggered by wheat harvest, which coincided with the time that the experiment was conducted. The relatively low proportion of spiders in woody remnant vegetation taking part in ballooning is in line with observations in a nearby study area showing that native plant species were dominated by non-ballooning spider groups (Parry et al. 2015). While native woody remnants may still contribute to the recruitment of grounddwelling spiders colonizing crops (Öberg and Ekbom 2006), we were not able to quantify cursorial movement with our sticky traps that were located $20 \mathrm{~cm}$ above the ground. Regression analysis further indicated that the contribution of spiders in sorghum, barley, and chick pea contribute little to crop immigration (Table 4; Online Appendix 3). Indeed, in most cases the spider densities in these crops were relatively low, and barley and chick pea covered only a low proportion of the landscape (Table 1). 
Table 2 Overview of model selection statistics for models predicting the number of spiders per trap using land use variables (proportion crops and proportion remnant vegetation; indicated in the white bars) or log-transformed spider load (estimated number of spiders in crops and remnant vegetation (RV); indicated in the grey bars)

\begin{tabular}{|c|c|c|c|}
\hline Scale & Model & df & $\mathrm{AIC}_{\mathrm{c}}$ \\
\hline \multirow[t]{2}{*}{$100 \mathrm{~m}$} & propcrop + AER + dewpoint + wind + year + offset & 1866 & 3535.8 \\
\hline & loadcrop + AER + dewpoint + wind + year + offset & 1866 & 3535.7 \\
\hline \multirow[t]{2}{*}{$500 \mathrm{~m}$} & propcrop + AER + dewpoint + wind + year + offset & 1866 & 3536.7 \\
\hline & loadRV + AER + dewpoint + wind + year + offset & 1866 & 3538.9 \\
\hline \multirow[t]{2}{*}{$1000 \mathrm{~m}$} & $\mathrm{AER}+$ dewpoint + wind + year + offset & 1867 & 3538.9 \\
\hline & loadcrop + AER + dewpoint + wind + year + offset & 1866 & 3523.4 \\
\hline \multirow[t]{2}{*}{$1500 \mathrm{~m}$} & AER + dewpoint + wind + year + offset & 1867 & 3538.9 \\
\hline & loadRV + loadcrop + AER + dewpoint + wind + year + offset & 1865 & 3518.6 \\
\hline \multirow[t]{2}{*}{$2000 \mathrm{~m}$} & $\mathrm{AER}+$ dewpoint + wind + year + offset & 1867 & 3538.9 \\
\hline & loadRV + loadcrop + AER + temp + wind + offset & 1866 & 3500.9 \\
\hline
\end{tabular}

The capacity of spiders to travel effectively by ballooning strongly depends on meteorological conditions. Low wind speeds and high differences in daily minimum and maximum temperatures are considered good conditions for ballooning (Vughts and Wingerden 1976; Reynolds et al. 2007). Wind speed, aeronautic index, dew point temperature and temperature were often selected in models (Table 1), confirming the importance of meteorological conditions for ballooning. Model selection indicated that landscape variables at a scale of $2000 \mathrm{~m}$ radius received more support from the data than landscape variables at smaller spatial scales (Table 2; Fig. 3). This suggests that spiders captured on traps often originated from distant locations. This finding is in line with studies that report high dispersal capacity for several ballooning spider families including Linyphiidae, Lycosidae and Tetragnathidae (Schmidt and Tscharntke 2005a;
Schmidt et al. 2008), which are the dominant ballooning spider families in southeast Queensland (Pearce et al. 2005). Interestingly, the variable "Year" was selected for most models, but with some notable exceptions (Tables 2, 3 and 4). Rainfall patterns in 2007 and 2008 were distinctly different; 2007 was the last dry year in a seven-year drought sequence, whereas in 2008 there were extended periods of rain. Most likely, spider populations in 2008 were boosted by a more lush vegetation supporting higher prey densities. Indeed, thrips, which are preyed upon by Linyphiid spiders (Harwood et al. 2004), were 3.4 more abundant on sticky traps in 2008 than in 2007 (Bianchi et al., unpublished data), providing a suitable food resource and potentially allowing a fast spider population build-up in 2008 . Yet, the biophysically naïve variable "Year" was not selected in the models based on spider load variables at 


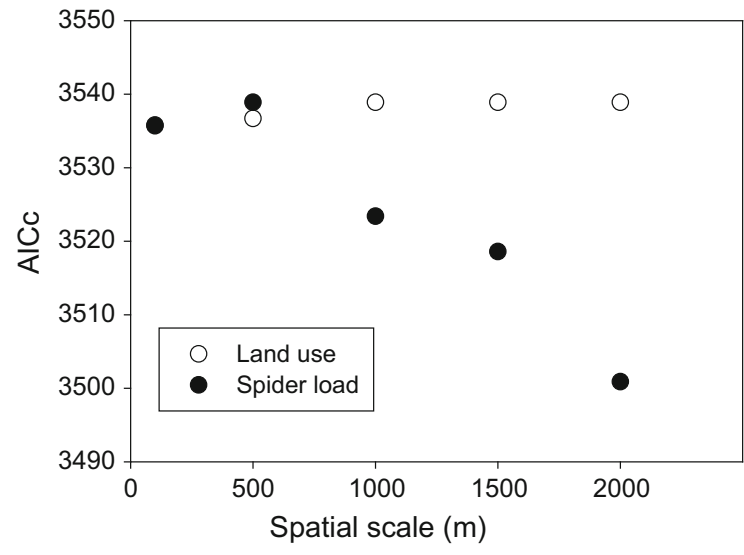

Fig. 3 Corrected AIC $\left(\mathrm{AIC}_{\mathrm{c}}\right)$ values for most parsimonious models predicting the number of spiders per trap using land use variables (proportion crops and proportion remnant vegetation; white markers) or log-transformed spider load values (estimated spider load in crops and remnant vegetation; black markers) at five spatial scales. Low $\mathrm{AIC}_{\mathrm{c}}$ values indicate high support from data. As a rule of thumb, if the difference in $\mathrm{AIC}_{\mathrm{c}}$ between two models is less than 2, the model with the higher $\mathrm{AIC}_{\mathrm{c}}$, though less good than the model with the lowest AIC, still has considerable support from the data. If $\Delta \mathrm{AIC}_{\mathrm{c}}>4$, the model with the higher AIC has considerably less support from the data than the model with the lower $\mathrm{AIC}_{\mathrm{c}}$

Table 3 Determinants of spider immigration rates into crops

\begin{tabular}{lccc}
\hline & Estimate & Lower 95\% CI & Upper 95\% CI \\
\hline Intercept & -17.4 & -19.7 & -15.2 \\
Spider load crop & 0.476 & 0.415 & 0.538 \\
Spider load RV & 0.161 & 0.0793 & 0.245 \\
AER & 0.149 & 0.0667 & 0.232 \\
Wind & 0.0876 & 0.0407 & 0.135 \\
Temp & 0.0694 & 0.0257 & 0.113 \\
\hline
\end{tabular}

Model estimates and 95\% confidence intervals (on a natural logarithm scale) of the most parsimonious model based on logtransformed spider load in crops and remnant vegetation (RV), meteorological variables (aeronautic index (AER), wind, and temperature) and the offset variable log-exposure hours. The model has an $\mathrm{AIC}_{\mathrm{c}}=3500.9$ and a negative binominal error distribution with $k=2.251$ and has an overall mean of 0.552 spiders per trap

a scale of $2000 \mathrm{~m}$ (Tables 3, 4), indicating that spider load in crops and remnant vegetation can explain the variation in spider immigration in crop fields between 2007 and 2008. Overall, our study confirms that spider immigration is driven by the interplay between meteorological conditions and functional cover types in the landscape (Thorbek and Topping 2005; Fahrig et al. 2011).
Table 4 Determinants of spider immigration rates into crops

\begin{tabular}{llll}
\hline & Estimate & $\begin{array}{l}\text { Lower 95\% } \\
\text { CI }\end{array}$ & $\begin{array}{l}\text { Upper 95\% } \\
\text { CI }\end{array}$ \\
\hline Intercept & -16.8 & -19.6 & -14.1 \\
Spider load wheat & $4.04 \times 10^{-1}$ & $3.54 \times 10^{-1}$ & $4.55 \times 10^{-1}$ \\
Spider load RV & $1.89 \times 10^{-1}$ & $8.88 \times 10^{-2}$ & $2.91 \times 10^{-1}$ \\
Spider load barley & $-2.43 \times 10^{-2}$ & $-3.73 \times 10^{-2}$ & $-1.13 \times 10^{-2}$ \\
Spider load chick & $-2.81 \times 10^{-2}$ & $-4.48 \times 10^{-2}$ & $-1.16 \times 10^{-2}$ \\
$\quad$ pea & & & \\
AER & $2.36 \times 10^{-1}$ & $1.12 \times 10^{-1}$ & $3.60 \times 10^{-1}$ \\
Wind & $1.89 \times 10^{-1}$ & $9.35 \times 10^{-2}$ & $2.86 \times 10^{-1}$ \\
Dew point & $7.99 \times 10^{-2}$ & $3.02 \times 10^{-2}$ & $1.30 \times 10^{-1}$ \\
$\quad$ temperature & & & \\
\hline
\end{tabular}

Model estimates and $95 \%$ confidence intervals (on a natural logarithm scale) of the most parsimonious model based on logtransformed spider loads in wheat, sorghum, barley, chickpea and woody remnant vegetation (RV), meteorological variables (aeronautic index (AER), wind, and dew point temperature) and the offset variable log-exposure hours. The model has an $\mathrm{AIC}_{\mathrm{c}}$ of 3489.8 and a negative binominal error distribution with $k=2.418$ and has an overall mean of 0.552 spiders per trap

There is growing consensus that the management of ecosystem services such as pest control and pollination can benefit from a better mechanistic understanding of the underlying processes (Kremen 2005; Schellhorn et al. 2014). Our study shows that immigration rates of ballooning spiders are positively related to the population size of spiders in the surrounding landscape at a spatial scale of $2000 \mathrm{~m}$ and possibly beyond. This implies that crop immigration could be stimulated by increasing the area of spider reproduction habitat and limit management practices that are harmful for spiders at the landscape scale.

Acknowledgements We thank Anna Marcora, Andrew Hulthen, Lynita Howie, Norm Winters, Karen Stanford and Kylie Lukins for field assistance and data collection and arthropod identification, as well as the landholders for their support. This research was financially supported by the Cotton Catchment Communities Cooperative Research Centre and Land and Water Australia.

Open Access This article is distributed under the terms of the Creative Commons Attribution 4.0 International License (http:// creativecommons.org/licenses/by/4.0/), which permits unrestricted use, distribution, and reproduction in any medium, provided you give appropriate credit to the original author(s) and the source, provide a link to the Creative Commons license, and indicate if changes were made. 


\section{References}

Bianchi FJJA, Schellhorn NA, Buckley Y, Possingham HP (2010) Spatial variability in ecosystem services: simple rules for predator mediated pest suppression. Ecol Appl 20:2322-2333

Bianchi FJJA, Schellhorn NA, Cunningham SA (2012) Habitat functionality for the ecosystem service of pest control: reproduction and feeding sites of pests and natural enemies. Agric For Entomol 15:12-23

Bianchi FJJA, Walters BJ, ten Hove ALT, Cunningham SA, van der Werf W, Douma JC, Schellhorn NA (2015) Earlyseason crop colonization by parasitoids is associated with native vegetation, but is spatially and temporally erratic. Agr Ecosyst Environ 207:10-16

Burnham KP, Anderson DR (2002) Model selection and multimodel inference: a practical information-theoretic approach. Springer, New York

Chaplin-Kramer R, O'Rourke ME, Blitzer EJ, Kremen C (2011) A meta-analysis of crop pest and natural enemy response to landscape complexity. Ecol Lett 14:922-932

Clough Y, Kruess A, Kleijn D, Tscharntke T (2005) Spider diversity in cereal fields: comparing factors at local, landscape and regional scales. J Biogeogr 32:2007-2014

Encyclopædia Britannica (2015) Bookdepository.com. Retrieved 14 July 2015

Entling MH, Stämpfli K, Ovaskainen O (2011) Increased propensity for aerial dispersal in disturbed habitats due to intraspecific variation and species turnover. Oikos 120:1099-1109

Fahrig L, Baudry J, Brotons L, Burel FG, Crist TO, Fuller RJ, Sirami C, Siriwardena GM, Martin J (2011) Functional landscape heterogeneity and animal biodiversity in agricultural landscapes. Ecol Lett 14:101-112

Gavish-Regev E, Lubin Y, Coll M (2008) Migration patterns and functional groups of spiders in a desert agroecosystem. Ecol Entomol 33:202-212

Harwood JD, Sunderland KD, Symondson WOC (2004) Prey selection by linyphiid spiders: molecular tracking of the effects of alternative prey on rates of aphid consumption in the field. Mol Ecol 13:3549-3560

Holzschuh A, Dormann CF, Tscharntke T, Steffan-Dewenter I (2013) Mass-flowering crops enhance wild bee abundance. Oecologia 172:477-484

Kremen C (2005) Managing ecosystem services: what do we need to know about their ecology? Ecol Lett 8:468-479

Macfadyen S, Banks JE, Stark JD, Davies AP (2014) Using semifield studies to examine the effects of pesticides on mobile terrestrial invertebrates. Annu Rev Entomol 59:383-404

Öberg S, Ekbom B (2006) Recolonisation and distribution of spiders and carabids in cereal fields after spring sowing. Ann Appl Biol 149:203-211

Parry HR, Macfadyen S, Hopkinson JE, Bianchi FJJA, Zalucki MP, Bourne AS, Schellhorn NA (2015) Plant composition modulates arthropod pest and predatorabundance: evidence for culling exotics and planting natives. Basic Appl Ecol 16:531-543

Pearce S, Zalucki MP, Hassan E (2005) Spider ballooning in soybean and non-crop areas of southeast Queensland. Agr Ecosyst Environ 105:273-281

Pluess T, Opatovsky I, Gavish-Regev E, Lubin Y, Schmidt MH (2008) Spiders in wheat fields and semi-desert in the Negev (Israel). J Arachnol 36:368-373

Pluess T, Opatovsky I, Gavish-Regev E, Lubin Y, SchmidtEntling MH (2010) Non-crop habitats in the landscape enhance spider diversity in wheat fields of a desert agroecosystem. Agr Ecosyst Environ 137:68-74

Rand TA, Louda SA (2006) Spillover of agriculturally subsidized predators as a potential threat to native insect herbivores in fragmented landscapes. Conserv Biol 20:1720-1729

Reynolds AM, Bohan DA, Bell JR (2007) Ballooning dispersal in arthropod taxa: conditions at take-off. Biol Let $3: 237-240$

Schellhorn NA, Bianchi FJJA, Hsu CL (2014) Movement of entomophagous arthropods in agricultural landscapes: links to pest suppression. Annu Rev Entomol 59:559-581

Schmidt MH, Tscharntke T (2005a) Landscape context of sheetweb spider (Araneae : Linyphiidae) abundance in cereal fields. J Biogeogr 32:467-473

Schmidt MH, Tscharntke T (2005b) The role of perennial habitats for Central European farmland spiders. Agr Ecosyst Environ 105:235-242

Schmidt MH, Thies C, Nentwig W, Tscharntke T (2008) Contrasting responses of arable spiders to the landscape matrix at different spatial scales. J Biogeogr 35:157-166

Symondson WOC, Sunderland KD, Greenstone MH (2002) Can generalist predators be effective biocontrol agents? Annu Rev Entomol 47:561-594

Thies C, Tscharntke T (1999) Landscape structure and biological control in agroecosystems. Science 285:893-895

Thomas CFG, Brain P, Jepson PC (2003) Aerial activity of Linyphiid spiders: modelling dispersal distances from meteorology and behaviour. J Appl Ecol 40:912-927

Thorbek P, Topping CJ (2005) The influence of landscape diversity and heterogeity on spatial dynamics of agrobiont linyphiid spiders: an individual-based model. Biocontrol 50:1-33

Venables WN, Ripley BD (2002) Modern applied statistics with S, 4th edn. Springer, New York

Vughts HF, Wingerden WKRE (1976) Meteorological aspects of aeronautic behaviour of spiders. Oikos 27:433-444

Wissinger SA (1997) Cyclic colonization in predictably ephemeral habitats: a template for biological control in annual crop systems. Biol Control 10:4-15

Zuur AF, Ieno EN, Walker N, Saveliev AA, Smith GM (2009) Mixed effects models and extensions in ecology with R. Springer, New York 